\title{
Using Omeka and Neatline to Facilitate Student Research in a Core Literature Class
}

Catherine E. Saunders (csaunde1@gmu.edu)

English Department, George Mason University

COURSE GOALS FOR ENGH 202-004 (Spring 2015)
"AMERICAN WOMEN'S BESTSELLLERS: DIGITAL HUMANITIES PERSPECTIVES"

-Give students the chance to practice skills of close reading, analysis, and synthesis in a writing/rhetorical context different from that of the familiar "English paper."

-Provide a writing/rhetorical structure that facilitates making connections between the core texts of the class and contemporary historical documents.

-Highlight a key focus of the class -- the cultural significance of places and spaces, real and fictional, in the core texts under study-- through the use of digital mapping tools.

- Give students a preliminary taste of one form of original research performed by literary scholars.

-Introduce students to some digital humanities tools, and the ways they can be used to visually represent literary texts and their cultural/historical contexts.

-Give the instructor a chance to experiment with the possibilities, pedagogical and otherwise, of the Omeka/Neatline plattorm.

ENGH 202 - Texts and Contexts
ENGH 202 - Texts and Contexts
Credits: 3
Repeatable within Term
Studies literary texts within the framework of culture. Examines texts within such categories
as history, gender, sexuality, religion, race, class, and nation.
Fulfills Mason Core requirement in literature.
Prerequisite(s): 3 credits of $100-$ level English.
Notes: Builds on reading and writing skills taught in ENGH 201.
Hours of Lecture or Seminar per week: 3
Hours of Lab or Studio per week: 0
Click here for the Summer 2015 Schedule of Classes
Click here for the Fall 2015 Schedule of Classes

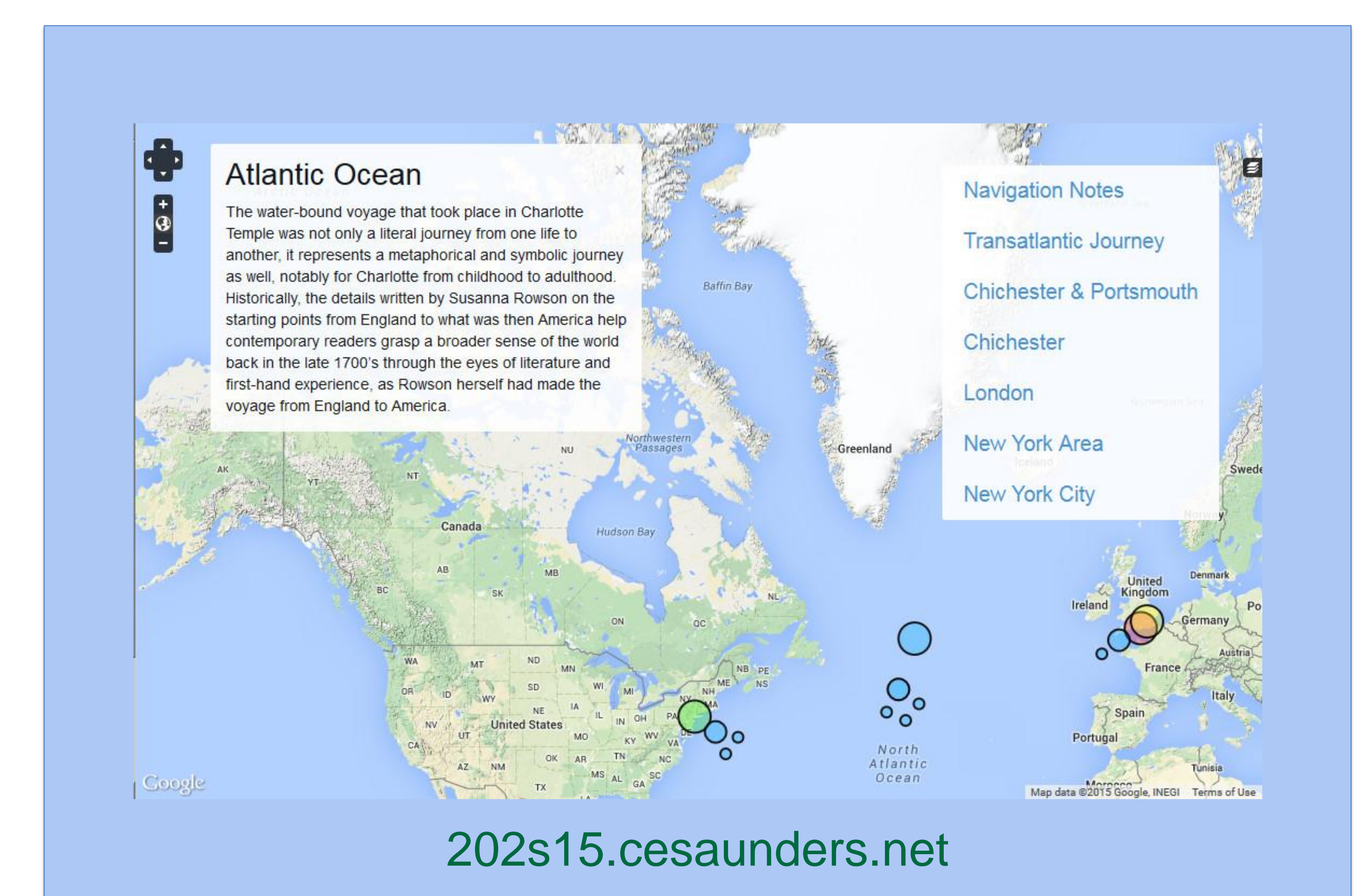

\section{RESULTS \& REFLECTION}

Successes:

- Most students were able to locate appropriate primary documents with only moderate difficulty in understand wh he concept andlor hy aspects of the novels under study.

-The assignment sequence scaffolded the process of locating and analyzing individual pieces of evidence, then drawing broader conlus

-Mapping spaces and places from the novels not only illuminated the significance of those ocations in the novels and the cultures from which they arose, but also revealed the

engagement of these "domestic" fictions with larger geopolitical events.

-Both item and exhibit assignments and the final exam encouraged original thought and

Issues \& Considerations:

- While students were able to explain factual connections between primary documents and literary texts, and to summarize the contents of both, they sometimes overgeneralized from limited evidence. In addition, many had difficulty moving beyond factual statements to
analysis and synthesis that engaged texts and contexts at a deeper symbolic/thematic level

-Due to time constraints, students did not place dots on the maps (and didn't for the most part provide detailed instructions for doing so). Making these decisions involves critical thinking about texts and how to represent them digitally; it would be worthwhile to have students

paricipale more aclively in he procoss.

-Items in a public Omeka/Neatline site must include, at the very least, accurate source and rights information; ensuring this level of correctness in
consume significant time both inside and outside class.

-Students in a core literature class may be resistant to trying something new in what is, for many of them, the last English class they expect to take. Resistance may manifest as doing
the minimum possible amount of work, increasing the need for corrections and revisions.
ASSIGNMENTS \& ACTIVITIES

-The class was held in a computer classroom with one computer per student, plus an instructor's computer/projector setup. Class time was divided more or less equally between sessions focusing on traditional in-class activities - brief lectures, whole-class discussion, and work on and presentation of Omeka/Neatline items and exhibits.

-After reading and discussing each of the four core texts, students brainstormed a list of mportant spaces and places in the text, and identified larger areas and subareas into which those space/places could be grouped. Students then signed up for area/subarea groups spaces/ places.

Each student located at least one primary document relevant to hisher chosen space or ctions on the item assignment/worksheet, created an Omeka item the

Groups worked together to fill out an Omeka worksheet for their assigned area, writing synthetic area and subarea introductions, adaing quotations from core texts to individual items, and determining where dots representing items, subareas, and areas should be placed. The exhibits to the class, then had an opportunity to revise before final grading.

Final exam questions drew on the Omeka/Neatline items and exhibits, asking students to incorporate references to specific items
of at least two of the core texts studied.

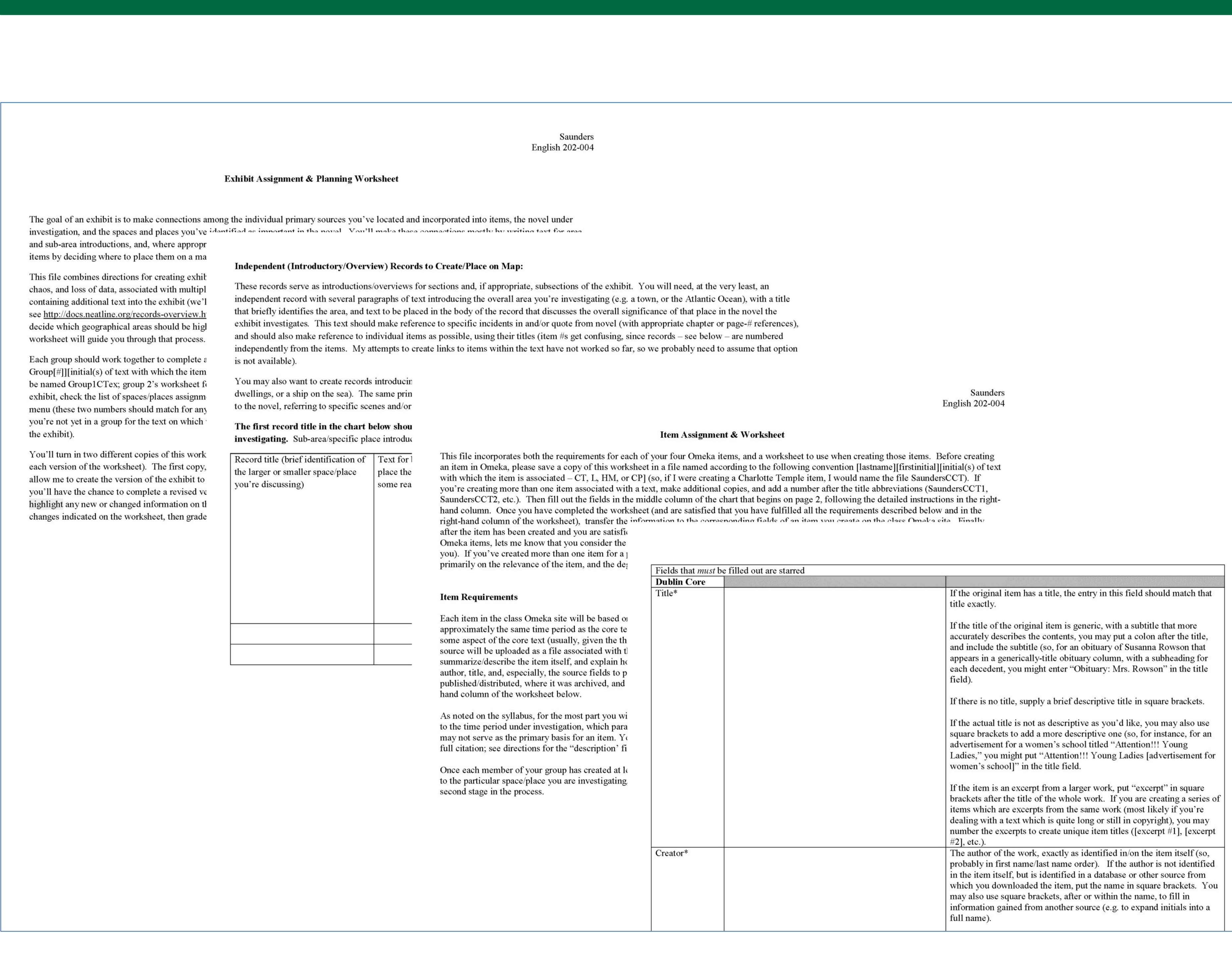

ACKNOWLEDGEMENTS

Thanks to the Term Faculty Development Fund, which provided funding for the development of the first teration of this class in Spring 2014 , and to my 